\title{
K-Means Kümeleme Yöntemi ile Konutlarda Kullanılan Elektrikli Cihazların Güç Tüketimi ve Harmonik Bileşenlerinden Karakter Analizi
}

\author{
Mustafa Şen YILDIZ ${ }^{1 *}$, Oktay ARIKAN², Ayșe Kübra ERENOĞLU ${ }^{3}$, Bedri KEKEZOĞLU ${ }^{4}$ \\ ${ }^{1}$ Elektrik-Elektronik Mühendisliği Bölümü, Mühendislik Fakültesi, Kırklareli Üniversitesi, Kırklareli, Türkiye \\ ${ }^{2,3,4}$ Elektrik Mühendisliği Bölümü, Elektrik-Elektronik Fakültesi, Yıldız Teknik Üniversitesi, İstanbul, Türkiye \\ ${ }^{* 1}$ mustafasenyildiz@klu.edu.tr, ${ }^{2}$ oarikan@yildiz.edu.tr, ${ }^{3}$ erenayse@ yildiz.edu.tr, ${ }^{4}$ bkekez@ yildiz.edu.tr
}

(Geliş/Received: 03/02/2020;

Kabul/Accepted: 21/10/2020)

Öz: Sanayileşmenin artması ve teknolojik gelişmeler, elektrik enerjisine olan ihtiyacı ve enerji kalitesine olan etkiyi artırmaktadır. Bu durum, elektriksel yüklerin izlenmesi ve kontrol edilmesi ihtiyacını doğurmaktadır. Konutlarda kullanılan elektrikli cihazların ölçüm ve denetimi amacıyla farklı akıllı ölçüm uygulamaları ve makine öğrenmesi algoritmaları denenmektedir. $\mathrm{Bu}$ çalışmada, evsel cihazların, temel güç tüketim parametreleri ve ürettikleri harmonik bileşenler dikkate alınarak, her bir cihazın güç tüketim karakterleri incelenmiștir. Ölçümler, K-Means kümeleme algoritması ile analiz edilmiştir. Analiz sonucunda, yeterli sayıda öznitelik dikkate alınması durumunda her bir cihazın güç tüketim karakterlerine ulaşılabileceği gözlemlenmiştir.

Anahtar kelimeler: Yük izleme, Harmonikler, Kümeleme, K-Means.

\section{Characteristics of Power Consumption and Harmonic Components of Electrical Appliances Used in Residences with K-Means Clustering Method}

\begin{abstract}
Industrialization and technological developments increase the need for electrical energy and the impact on energy quality. Therefore, it is needed to monitoring and controlling of electrical loads. Different intelligent measurement applications and machine learning algorithms are tried for measurement and control of electrical devices used in residences. In this study, the power consumption characteristic of each residential device are measured by considering the basic power consumption parameters and harmonic components. Measurements were analyzed by K-Means clustering algorithm. As a result of the analysis, it is observed that the power consumption characteristics of each device can be achieved if sufficient number of features are taken into account.
\end{abstract}

Key words: Load monitoring, Harmonics, clustering, K-Means.

\section{Giriş}

Elektrik enerjisinde kalite, akım ve gerilim dalga şekillerinin sürekli, dengeli ve saf sinüs olmasına, gerilimin efektif değeri ile frekansın sabit olmasına ve güç faktörünün 1'e yakın olmasına bağlıdır. Enerji kalitesi problemleri ise, yarı iletken malzemelerin kullanımına, güç sistemi üzerinde bulunan ekipman ve yüklere, meteorolojik unsurlara, vb. durumlara bağlı olarak; gerilim dengesizliği, kesinti, kırpışma (flicker), gürültü, geçici durumlar, harmonik bileşenler olarak sıralanabilir. Bu problemlerden biri olan harmonik bileşenler, dalga şekli bozulmasına, akım ve gerilimin efektif değerlerinin artmasına, arıza akımlarının yükselmesine, cihazlarda aşırı zorlanmalara ve kontrol-kumanda devrelerinde hatalı açmalara sebep olmaları nedeniyle en önemli kalite parametrelerindendir [1].

Kalite problemleri genel olarak meydana geldiği saha açısından iki gruba ayrılmaktadır. Birinci grup, iletim ve dağıtım sistemlerinden kaynaklanan gerilim çöküntülerini ve enerji kesintilerini içermektedir. İkinci grup ise evsel yüklerin büyük çoğunluğunu oluşturduğu müşteri tarafında meydana gelen dalga şekli bozulmalarını içermektedir.

Son yıllarda evsel yüklerin, genel şebeke içerisindeki ağırlığı da hızla artmaktadır. Birleşik Krallık’ta konut elektriğinin kullanımı genel şebeke içerisinde \%30 seviyelerine ulaşmış durumdadır [2]. Bu oranın Amerika Birleşik Devletleri'nde ise yaklaşık olarak \%23 civarında olduğu, 2030 yılında ise \%25'e ulaşacağı tahmin edilmektedir [3]. Bu yüklerde yarı iletken elemanların kullanımının artmasına da paralel olarak harmonik etkinin de artacağı açıktır. Bu durum dikkate alındığında, konutlarda tüketilen enerjinin denetimi ve yönetimi büyük bir

\footnotetext{
* Sorumlu yazar: mustafasenyildiz@ klu.edu.tr. Yazarların ORCID Numarası: ${ }^{1}$ 0000-0003-4176-9353, ${ }^{2}$ 0000-0002-3304-3766, ${ }^{3}$ 0000-00029578-6194, ${ }^{4} 0000-0002-1202-913 \mathrm{X}$
} 
gerekliliktir. Buna cevap verebilmek için literatürde, cihaz yükü izleme (Appliance Load Monitoring-ALM) konusunda, akıllı ölçüm cihazları ile ilgili çalışmalar gerçekleştirilmektedir [3],[4],[18]. ALM'nin amacı akıllı ölçüm cihazları kullanılarak evsel yüklerin anlık güç analizini yapmaktır. Akıllı sayaçların yaygınlaşmasına ve kullanıcı tüketimine ilişkin somut bilgilerin elde edilmesine bağlı olarak, tüketicinin tüketim şekli hakkındaki bilgiler, müşteri ve kamu işletmeleri için kalite iyileştirme, enerji verimliliği, özel tarifeler oluşturma, bir evin yaşam biçimini anlama ve talep cevabını düzenleme gibi pek çok konuda bilgi sağlamaktadır [6], [7].

ALM genel olarak, müdahaleci yük izleme (Intrusive Load Management-ILM) ve müdahaleci olmayan yük izleme (Non-Intrusive Load Management-NILM) olarak iki yaklaşımla gerçekleștirilmektedir. ILM yaklaşımında her elektronik cihazın bir sensör yardımıyla ölçümleri alınmakta ve detaylı şekilde analizi yapılmaktadır. Ancak, bu yöntem her ne kadar daha doğru sonuç veriyor olsa da yüksek maliyeti sebebiyle ticarileşme olasılığı azalmaktadır [5]. Diğer bir yaklaşım olan NILM ise her ev için sadece bir adet akıllı sayaç kullanılarak, evin çektiği toplam aktif güç, reaktif güç, güç faktörü, harmonik bileșenler vb. ölçümleri toplanmakta ve analizini yaparak evde hangi cihazların çalıştı̆ğını tahmin etmektedir [5], [7], [8], [19], [20]. Şekil 1'de bu sistemin genel akış diyagramı gösterilmektedir. Tahmin süreci, evsel yüklerin kendilerine özgü güç tüketimlerinin, toplam güçten ayrıştırılması işlemidir. Bu işlem için, neural networks [9], K-Means [10], hidden markov model [11], partical filter [12], vb. farklı makine ögrenmesi algoritmaları denenmektedir [13]

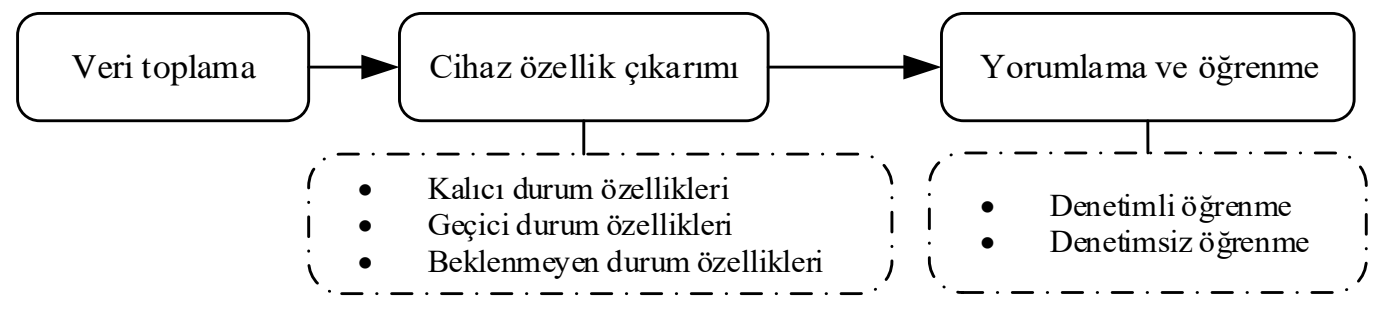

Şekil 1. NILM sisteminin genel akışı [5].

Tahmin sürecinde, birbirine yakın tüketim yapan cihazlar ve geçici durumlar problem oluşturmaktadır. Problemleri en aza indirmek için uygulanacak algoritmanın test verileri her bir cihazı kapsayacak şekilde ve bütün çalışma modlarını içerecek şekilde oluşturulmalıdır. Cihazların çalışma modlarına göre farklı güç değerleri çekecekleri dikkate alındığında bütün modlara ait ölçüm değerlerinin incelenmesi gerekmektedir. Bunun yanı sıra geçici ve beklenmeyen durumlar da dikkate alındığında tek bir evsel yük için bile onlarca farklı durum ölçümü gerekmektedir. Bu sebeple kümeleme yaparken denetimli öğrenme metodları kullanılarak her bir cihazın farklı modlarını ölçümlerinin alınması yerine denetimsiz öğrenme algoritmalarını kullanarak belirli aralıklar dâhilinde ve kabul edilebilir hata oranlarıyla kümeleme yapılabilir. Belirlenecek aralıkların her bir cihaz için özgün karakter oluşturması gerekmektedir. Aksi takdirde cihaz tahminlerinde yanılmalar olacaktır. Bu problemleri aşmak için cihazların ve çalışma modlarının öznitelikleri olan temel güç parametrelerine $(S, P, Q, \ldots)$ ek olarak harmonik bileşenler gibi ekipmana özgü parametreler de tahmin sürecine dahil edilmelidir.

Bu çalışmada, evsel cihazların güç tüketimindeki kendine özgü imzaları araştırılmıştır. Araştırma için Yıldız Teknik Üniversitesi (YTÜ) Elektrik Mühendisliği Bölümü bünyesinde bulunan akıllı ev laboratuvarında evsel cihazların detaylı ölçümleri yapılarak, gerçek ölçümler üzerinden kümeleme çalışması gerçekleştirilmiştir. Her cihaz için özellik sayısı arttıkça cihazlar arasında belirgin farklar oluştuğu gözlemlenmiştir.

Makalenin 2. bölümünde evsel yük ölçüm yöntemi, metodolojisi ve harmonik bileşenlerden bahsedilmiştir, 3. Bölümde, kümeleme yöntemi ve K-Means algoritması anlatılmıştır. 4. Bölümde veri analiz sonuçları yorumlanmıştır. Son bölümde ise sonuç ve öneriler aktarılmıştır.

\section{Metodoloji}

Bu bölümde, konutlarda kullanılan elektrikli cihazların karakter analizi için kullanılan veriler ile ilgili genel bilgiler verilmektedir. Analiz için ihtiyaç duyulan temel parametrelerin $(S, P, Q, \ldots$ ) yanında özellikle harmonik bileşenler de dikkate alınmaktadır. Çalışmada kullanılan temel parametrelerin ölçümü ve harmonik bileşenler hakkında bilgiler alt başlıklar halinde açıklanmıştır. 


\section{1 Ölçümler}

Evsel cihazların her birinin farklı güç karakteri vardır. Bu karakterlerin özgünlüğünü incelemek için cihazların şebekeden çektikleri aktif güç, reaktif güç ve harmonik bileşen ölçümleri yapılmıştır. Ölçümler Şekil 2'de gösterilen Fluke 435-II serisi 3 fazlı güç kalitesi analizörü ile gerçekleştirilmiş̧ir.

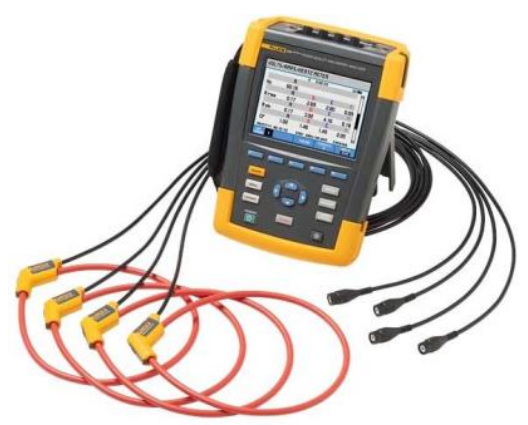

Şekil 2. Fluke 435-II.

Gerçekleştirilen çalışmada 17 adet evsel cihaz dikkate alınmıştır. Bu cihazlar Tablo 1'de sunulan etiket anma gücü değerleri ile birlikte belirtilmektedir. Ölçüm değerleri, cihazların çalışma modları göz önüne alınarak belirli zaman aralığı boyunca, her 3 saniyelik örnekleme periyodunda bir yapılmış ve ölçümlerin ortalamaları alınarak değer belirlenmiştir.

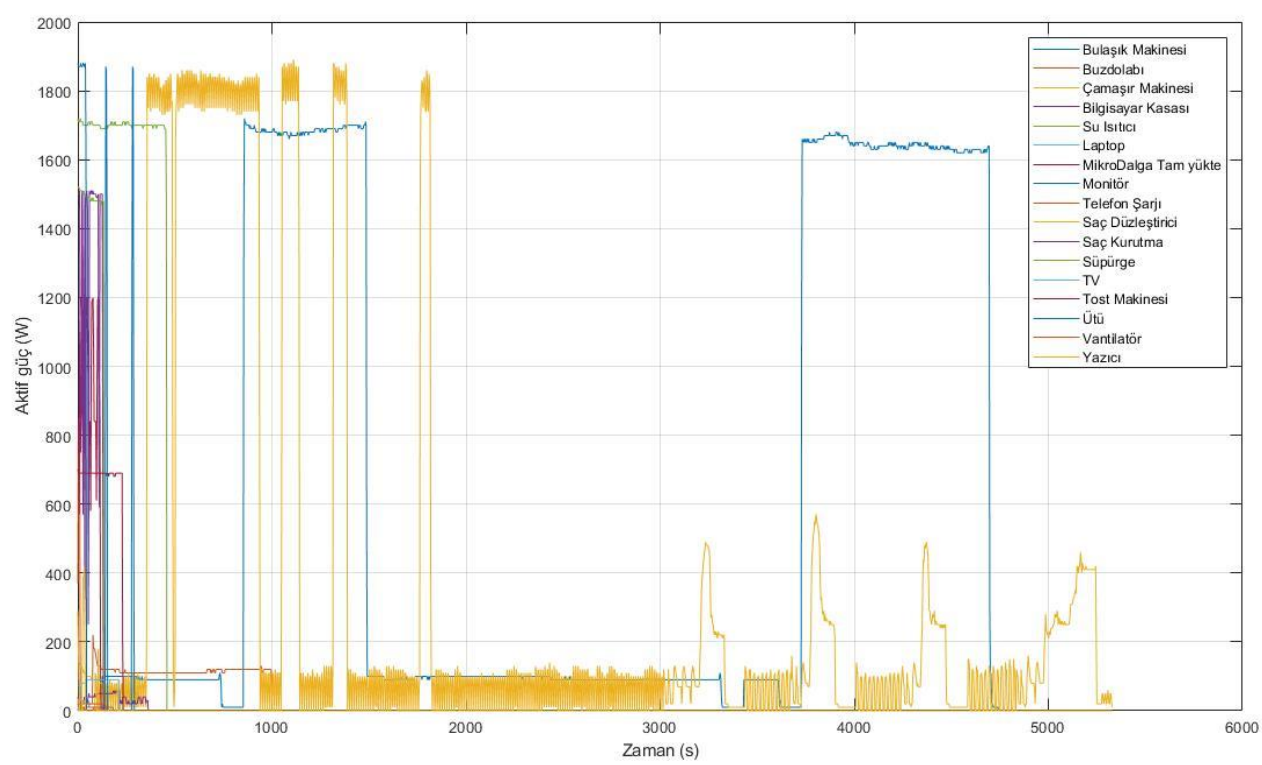

Şekil 3. Evsel cihazların çektikleri anlık güçler.

Alınan ölçümlerden elde edilen aktif güç, reaktif güç, görünür güç, güç faktörü, toplam harmonik bozulma, harmonik bileşen değerlerinin ortalamaları dikkate alınarak analizler gerçekleştirilmiştir.

Şekil 3'de cihazların ölçülen anlık aktif güç grafiği gösterilmektedir. Cihazlar içerisinden ortalama olarak en fazla güç tüketen cihaz $1677,48 \mathrm{~W}$ ile su 1sitıcı, en az güç tüketen cihaz ise $8,57 \mathrm{~W}$ ile telefon şarjı olduğu gözlemlenmiştir. 
Tablo 1. Ölçüm yapılan cihazlar ve anma güçleri.

\begin{tabular}{lc|lc}
\hline \multicolumn{1}{c}{ Cihaz } & $\begin{array}{c}\text { Anma Gücü } \\
(\mathrm{kW})\end{array}$ & \multicolumn{1}{c}{ Cihaz } & $\begin{array}{c}\text { Anma Gücü } \\
(\mathrm{kW})\end{array}$ \\
\hline Buzdolabı & 0.150 & Saç düzleştirici & 0.055 \\
Ütü & 2.4 & Firın & 2.05 \\
Tost makinesi & 0.708 & Bulaşık makinesi & 1.7 \\
Su 1sıtıcı & 2 & Mikrodalga firın & 1.18 \\
Saç kurutucu & 1.536 & Yazıcı & 0.02 \\
LCD-TV & 0.09 & Dizüstü bilgisayar & 0.03 \\
Bilgisayar kasası & 0.05 & Çamaşır makinesi & 1.8 \\
Bilgisayar monitörü & 0.03 & Elektrikli süpürge & 1.9 \\
LED Aydınlatma & 0.035 & & \\
\hline
\end{tabular}

Programlı cihazlarda, örneğin çamaşır makinesinde, bir program süresi boyunca ölçüm alınmıştır. Programlı olmayan cihazlar için ise günlük kullanım tahmini yapılarak belirlenen süreler boyunca ölçümler alınmıştır.

\subsection{Harmonikler}

Harmonikler genel olarak, temel frekansın (Türkiye için $50 \mathrm{~Hz}$ ) dışında temel frekansın tam katı frekanslardaki sinüzoidal akım veya gerilim bileşenleridir. Evsel cihazlardaki aktif devre elemanları harmonik etkiye sebep olmakta ve dalga şeklini bozmaktadır. Bu durum, güç kalitesini ve verimliliği azaltmaktadır. Ancak, cihaz karakteristiğini belirleme açısından bakıldığında, karakteristiklerin belirlenmesi açısından, harmonik etkilerin dikkate alınması önem arz etmektedir.
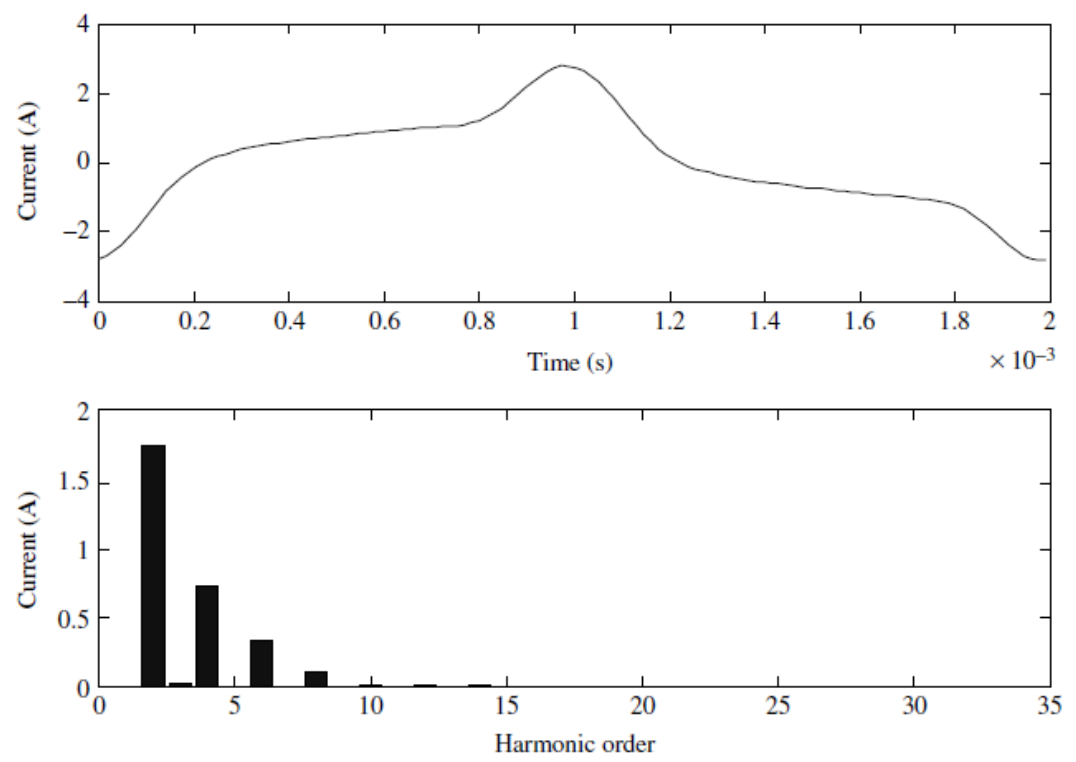

Şekil 4. Ayrık zamanlı fourier dönüşümü [17].

Harmonik bileşenlerin belirlenmesinde bütünleşik bir dalgacığı, alt frekanslardaki dalga bileşenlerine ayırmak için farklı yöntemler kullanılmaktadır. Bu çalışmada kullanılan güç analizörü, Fast Fourier Transform (FFT) modeliyle alt bileşenleri göstermektedir. Bu matematiksel model, (1) denkleminde gösterilmektedir. Denklemdeki $N$, bir periyotta kaç adet eşit uzaklıkta örnekleme noktası alındığını belirtmektedir. Zaman boyutundaki bir dalganın frekans boyutunda FFT karşılı̆̆ Şekil 4'te gösterildiği şekilde modellenmektedir.

$X_{k}=\sum_{n=0}^{N-1} x_{n} e^{-\frac{i 2 \pi k n}{N}} \quad k=0,1, \ldots, N-1$ 
Toplam harmonik bozulma (2) denkleminde gösterilen formülden hesaplanmakla birlikte Tablo 2'de ölçüm yapılan bütün cihazlara ait toplam harmonik bozulmalar belirtilmiştir.

$T H D_{I}=\frac{\sqrt{\sum_{I=2}^{\infty} I_{h}^{2}}}{I_{1}}$

Toplam harmonik bozulmanın etkisinin yanı sıra her bir bileşen için harmonik bozulmanın etkisi de (3) denklemi ile bulunmaktadır.

$H_{I}(h)=\frac{I(h)}{I_{1}}, h=$ harmonik derecesi

Ölçüm yapılan cihazların her biri için harmonik bozulmalar ölçülmüş ve analiz bölümünde detaylı olarak irdelenmiştir.

\section{Kümeleme Analizi}

Kümeleme algoritmaları, veri madenciliğinde kullanılan denetimsiz öğrenme yöntemlerinden biridir. $\mathrm{Bu}$ yöntemin hastalık tedavilerini sınıflandırma, tıbbi görüntüleme, pazar bölümleme, örüntü tanıma, görüntü işleme, sosyal medya analizi gibi birçok farklı alanda uygulaması mevcuttur.

Kümeleme en genel anlamda, çok boyutlu nesnelerin benzerlik ölçüsü yardımıyla benzer özelliklerine göre ayırt edilmesi ve gruplandırılması işlemidir. Amaç, küme içi benzerliğin en yüksek, kümeler arası benzerliğin ise en düşük olmasını sağlamaktır. Bu işlem için n adet veri örneğinin her birinin p adet özelliği olduğunu varsayarsak, $\mathrm{p}$ adet boyut boyunca $\mathrm{n}$ adet veri durum uzay düzleminde örneklenmektedir.

Örnek veri seti $X=\left\{x_{1}, x_{2}, x_{3}, \ldots, x_{n}\right\}, n * p$ boyutlu veri matrisi şeklinde de gösterilebilmektedir. Bu gösterim (4) denkleminde verilmiştir. Burada $x_{i j}$, $i$ 'nci veri için $j$ 'nci özelliği ifade etmektedir [10].

$X=\left[\begin{array}{ccc}x_{11} & \cdots & x_{1 p} \\ \vdots & \ddots & \vdots \\ x_{n 1} & \cdots & x_{n p}\end{array}\right]$

Yukarıda bahsedilen benzerlik ölçüsü, Manhattan ((5) eşitliğinde gösterilmektedir.), Öklid ((6) eşitliğinde gösterilmektedir.), Minkowski ((7) eşitliğinde gösterilmektedir.), vb. uzaklık ölçüm fonksiyonlarıdır [11].

$d(x, y)=\sum_{k=1}^{p}\left|x_{k}-y_{k}\right|$

$d(x, y)=\left(\sum_{k=1}^{p}\left(x_{k}-y_{k}\right)^{2}\right)^{1 / 2}$

$d(x, y)=\left(\sum_{k=1}^{p}\left(x_{k}-y_{k}\right)^{\alpha}\right)^{1 / \alpha}$

Örnekte bahsedilen $p$ boyutlu $n$ adet veri, pek çok farklı yöntemle kümelenmektedir. Genel anlamda bu yöntemler hiyerarşik ve hiyerarşik olmayan olmak üzere ikiye ayrılmaktadır [12].

Hiyerarşik kümelemenin, Yığınsal (Agglomerative) ve Bölücü (Divisive) olarak iki farklı varyasyonu vardır. Yığınsal yönteminde her bir veri bir küme olarak kabul edilerek yakınlıklarına göre birleştirilirler. Bölücü yöntemde ise tam tersi yönde hareket eder ve sonuçlar küme ağaçları veya dendrogramlar şeklinde görselleştirilirler.

Hiyerarşik olmayan kümeleme yöntemleri ise veri setini, belirli ölçütleri minimize ederek istenilen $\mathrm{k}$ adet kümeye bölmektedir. Bu bölümlemeyi yaparken yukarıda bahsedilen uzaklık fonksiyonları kullanılmaktadır [12]. Hiyerarşik olmayan kümeleme içerisinde K-Means algoritması en çok tercih edilen algoritmadır.

\subsection{K-Means algoritması}

K-Means kümeleme yöntemi, n adet verinin, her örneğin kendine en yakın olduğu k tane kümeye ayrılmasını amaçlayan bir yöntemdir. Bu yöntemle, başlangıçta en iyi k adet küme bilinmese bile küme adedine müdahale 
edilerek uygun küme sayısı belirlenebilmektedir. En iyi k adet küme, küme içi varyantı veya SSE fonksiyonunu en aza indirmekle bulunmaktadır. K-Means algoritmasının ana fonksiyonu eşitlik (8)'de gösterilmiştir.

$J=\sum_{j=1}^{k} \sum_{i=1}^{n}\left\|x_{i}^{(j)}-c_{j}\right\|^{2}$

Bu fonksiyonda belirtilen $J$, ana fonksiyonu; $j=\{1,2, \ldots, k\}$, küme adedini; $i=\{1,2, \ldots, n\}$, veri adedini; cj, j. küme merkezini ve xi, verinin boyutsal olarak yerini göstermektedir. Veri noktası (xi), p boyutlu uzaya sahiptir ve verinin sahip olduğu özellik adedine göre değişmektedir. Algoritma aşamaları genel olarak Şekil 5'de belirtilen adımlardan oluşmaktadır.

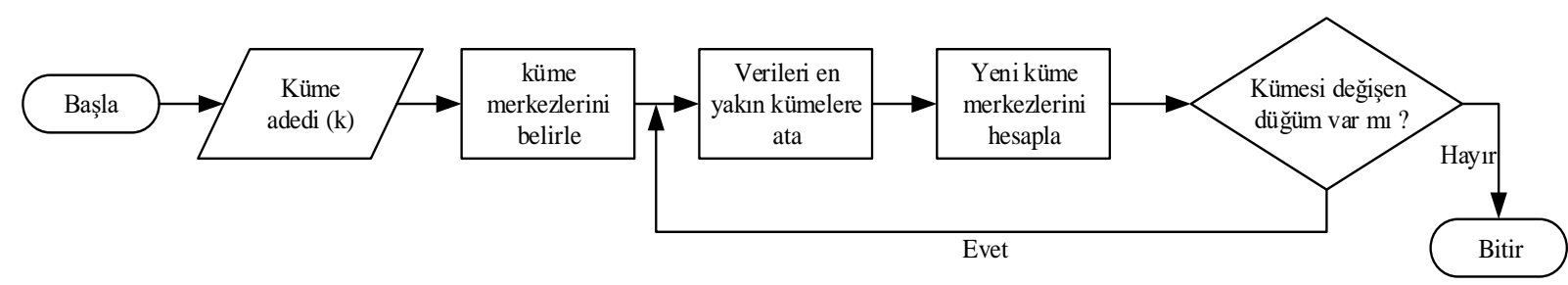

Şekil 5. K-Means algoritması akış şeması.

K-Means algoritmasının girdileri, cihazların yük profillerini ve maksimum küme sayısını içerir. Maksimum küme sayısı her zaman giriş yükü profillerinin sayısına eşittir. Maksimum küme sayısına ulaşılması durumunda, her yük profili kendi kümesine sahip olacaktır. Yük profilleri bu durumda kümelerinin merkezleridir. Algoritma her bir yinelemesinde, denklem (6) 'ya göre yük profilleri ve küme merkezleri arasındaki ortalama Öklid mesafesini hesaplar. Bu, her yük profilinin en yakın merkeze sahip kümeye atanmasını sağlar.

\subsection{Kare Hata Toplamı}

Kare hata toplamı (SSE) istatistiksel verisi, yöntemin performansını kıyaslamada önemli bir ölçüttür. Bu veri, her zaman pozitif değer almakla birlikte ideal değeri sıfıra yakın olandır. Eşitlik (9)'da gösterilen denklemle hesaplanmaktır. $\mathrm{Bu}$ denklemde $x, c_{j}$ kümesindeki boyutsal veriyi; $\mu_{j}$ ilgili verinin atandığ merkezini belirtmektedir.

$S S E=\sum_{j=1}^{k} \sum_{x \epsilon C_{j}}\left(\mu_{j}-x\right)^{2}$

Yük profilleri ve karşılık gelen küme merkezleri arasındaki kare hata toplamı (SSE) değeri, optimum küme sayısını belirlemek için bir ölçüt olarak kullanılmaktadır.

Algoritma analizinden sağlıklı sonuç elde etmek için küme sayısının belirlenmesi ve kare hata toplamı (Sum of Squared Error - SSE) minimum seviyede tutulması çok önemlidir.

Tablo 2. Evsel cihazların ölçüm değerleri.

\begin{tabular}{|c|c|c|c|c|c|c|c|}
\hline Cihaz & $\begin{array}{l}\text { Aktif güç } \\
\text { (W) }\end{array}$ & $\begin{array}{c}\text { Reaktif } \\
\text { güç } \\
\text { (WAr) }\end{array}$ & $\mathrm{THD}_{\mathrm{i}}$ & Cihaz & $\begin{array}{l}\text { Aktif güç } \\
\text { (W) }\end{array}$ & $\begin{array}{l}\text { Reaktif güç } \\
\text { (WAr) }\end{array}$ & THD $_{\mathrm{i}}$ \\
\hline Bulaşık Makinesi & 235.4 & -8.01 & 28.59 & Saç Düzleştirici & 83.4 & -20 & 23.02 \\
\hline Buzdolab1 & 117.1 & 44.68 & 19.17 & Saç Kurutma & 1222.6 & -24.78 & 4.4 \\
\hline Çamaşır Makinesi & 331.6 & 132.6 & 54.60 & Süpürge & 1399.1 & 104.3 & 21.38 \\
\hline Bilgisayar Kasası & 36.9 & -23.14 & 43.87 & TV & 84.08 & -19.15 & 20.07 \\
\hline $\mathrm{Su}$ Isitic1 & 1677.48 & -39.41 & 3.74 & Tost Makinesi & 674.4 & -19.4 & 3.2 \\
\hline Dizüstü Bilgisayar & 22.79 & -10 & 165.2 & Ütü & 360.7 & -17.38 & 15.4 \\
\hline Mikrodalga Fırın & 916.09 & -11.70 & 15.92 & Vantilatör & 19.4 & 29 & 14.4 \\
\hline Monitör & 10 & 0 & 134.3 & Yazıcı & 135.6 & -6.8 & 48.5 \\
\hline Telefon Şarj Cihazı & 8.57 & 0 & 153.1 & & & & \\
\hline
\end{tabular}




\section{4. Ölçüm ve Analizler}

Evsel cihazların temel elektriksel öznitelikleri (S, P, Q, ...) kullanılarak yapılan kümeleme, cihaz sayısı arttıkça ve cihazların farklı çalışma modları eklendikçe, özgün karakter çıkarımı için yeterli olmamaktadır. Ancak harmonik bileşenlerin eklenmesi daha başarılı sonuçlar ortaya çıkarmaktadır.

Analizi yapılan cihazların aktif güç, reaktif güç ve toplam harmonik akım bozulma $\left(\mathrm{THB}_{\mathrm{I}}\right)$ ölçüm değerleri Tablo 2'de gösterilmektedir. Sadece bu üç verinin kullanılması bile özgün karakter tahmini açısından belirgin farklar sunmaktadır. Ancak, gerek farklı çalışma modları, gerekse cihaz sayısının artacak olması, daha ayrıntılı analiz yapma ihtiyacı doğurmaktadır.

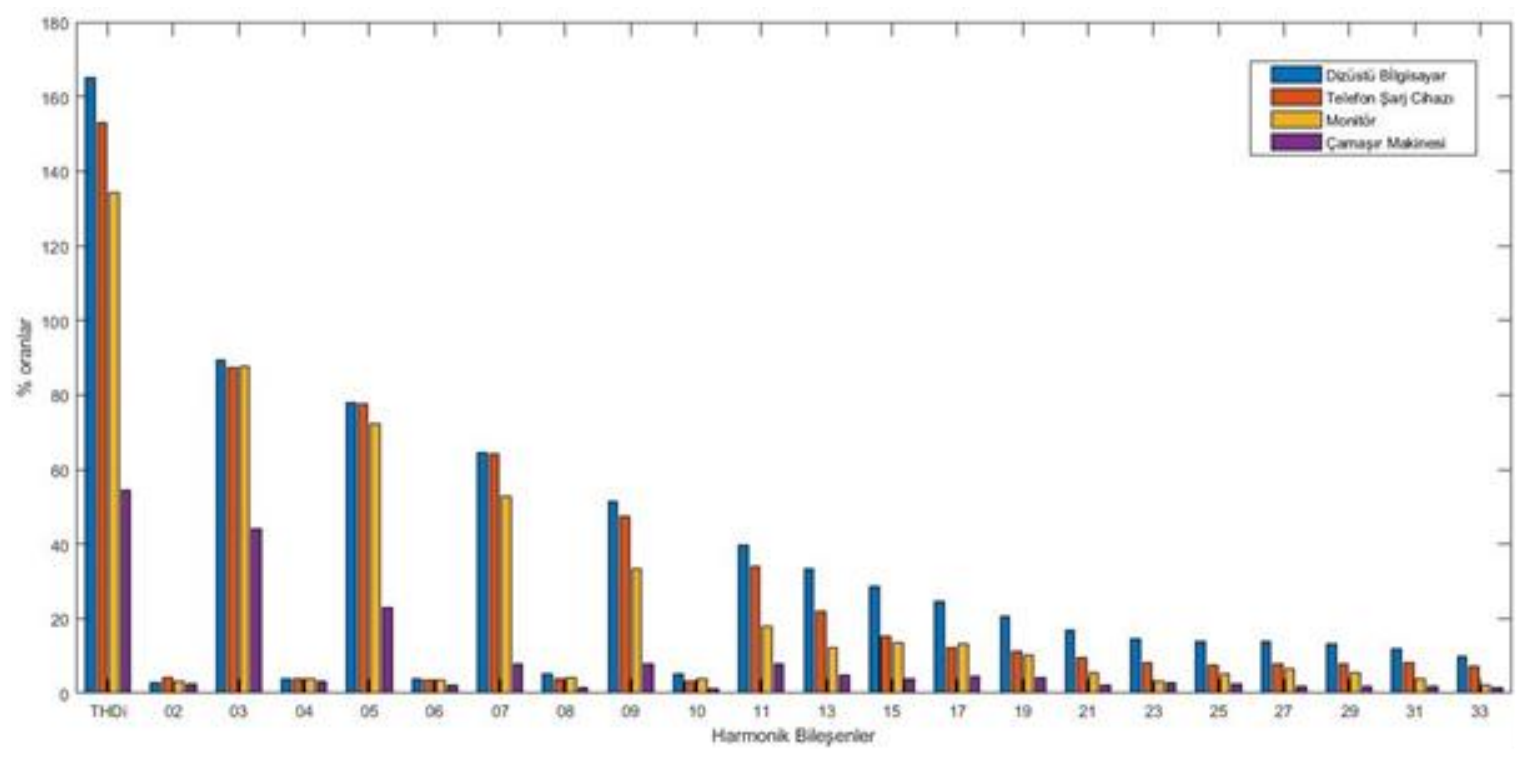

Şekil 6. Evsel cihazların harmonik bileşenleri.

Ölçümleri alınan 17 adet evsel cihaz, Weka programı ile K-Means algoritması kullanılarak, 9 farklı öznitelik senaryosu için gruplandırılmıştır. Bu öznitelik senaryolarında, aktif güç $(\mathrm{P})$, reaktif güç $(\mathrm{Q})$, görünür güç $(\mathrm{S})$, güç faktörü (PF), toplam harmonik bozulma (THD), $\cos \varphi$ değerleri ve belirli harmonik bileşenler $\left(\mathrm{H}_{2}, \mathrm{H}_{3}, \mathrm{H}_{5}, \mathrm{H}_{7} \mathrm{H}_{9}\right.$, $\mathrm{H}_{11}, \mathrm{H}_{13}, \mathrm{H}_{15}, \mathrm{H}_{17}, \mathrm{H}_{19}, \mathrm{H}_{21}$ ) değişken olarak kullanılmıştır. Her senaryo için 17 adet cihaz 6'dan 17'ye kadar alt gruplara ayrılmış ve gruplandırma sonucunda hesaplanan SSE değerleri Tablo 3'de belirtilmiştir.

Tablo 3 incelendiğinde SSE değerlerinin, soldan sağa doğru gidildiğinde azaldığı ve yukarıdan aşağıya doğru gidildikçe ise arttı̆̆ görülmektedir. Satırlar kendi içinde incelendiğinde, 0,5 SSE değerini eşik olarak belirlenmesi durumunda, harmonik bileşenlerin dikkate alınmadığı 1. ve 2. senaryoda, 8 alt grupta, 4. Senaryoda 11 grupta, 58 arası senaryolarda 13 grupta ve son olarak 9 . Senaryo da ise 14 grupta eşik değerin altına düşüldüğü görülmektedir. Sütunlara bakıldığında ise cihazlar 15 gruba ayrılırsa (1. senaryodan 9. senaryoya doğru bakıldığında), 1. senaryoda 0,04 olan SSE değeri 9 . Senaryoda 0,25 'e yükselmektedir. Bu durum, öznitelikler arttığında cihazların ayrı gruplarda toplanma eğiliminde olduğunu belirtmektedir. Yani öznitelik sayısı arttıkça cihazların enerji tüketim karakterleri farklılaşmaktadır.

15. ve 16. gruplar daha detaylı incelendiğinde, aynı gruba dâhil olan cihazlar Tablo 4'te gösterilmektedir. 16. grup için bütün cihazların faklı gruplara dağıldığı; ancak 2-8 arası senaryolarda, mikrodalga firın ile tost makinesinin aynı grupta, 1. ve 9. senaryoda ise mikrodalga firın ile saç kurutma makinesinin aynı grupta yer aldığı görülmektedir. Bu sonuç, harmonik bileşenler öznitelik olarak dikkate alınmadığında mikrodalga firın ile saç kurutma makinesinin enerji tüketimlerinin birbirine yakın olduğunu göstermektedir. Ancak harmonik bileșenler dikkate alınırsa mikrodalga firın ile tost makinesinin enerji tüketim parametrelerinin birbirine yakın olmakta, bu karşın bu iki cihazın harmonik bileşen parametreleri incelendiğinde 3. ve 5. harmonik bileşenlerinde net farklar ölçüldüğü görülmektedir. 
Tablo 3. Evsel cihazların özelliklerine göre kümeleme sonuçlarının kare hata oranları.

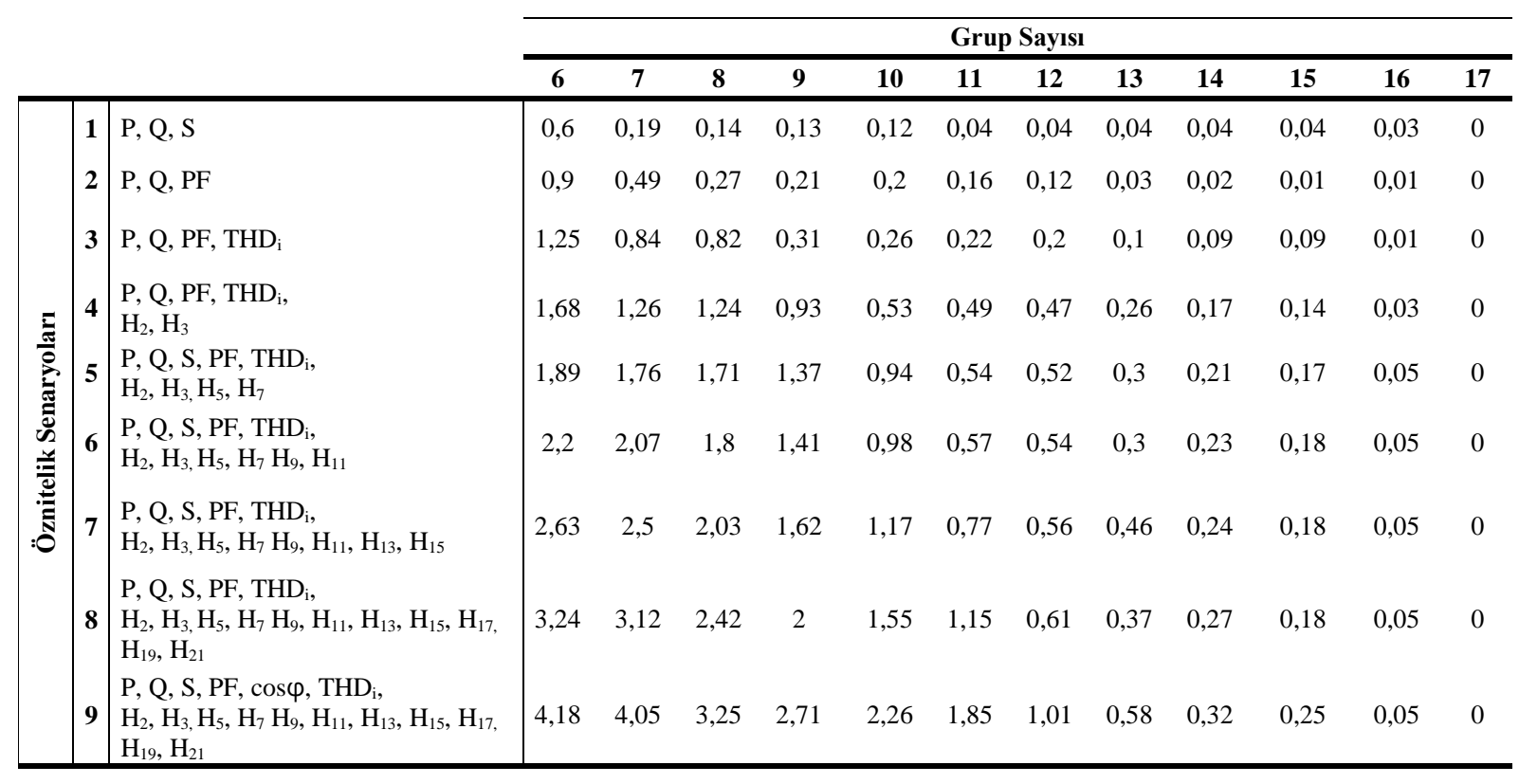

15. grupta ise 4-8 arası senaryolarda, mikrodalga firın ile tost makinesinin bir grupta ve buna ek olarak buzdolabı ile vantilatörün ise başka bir grupta toplandığı 1 . ve 9. senaryoda mikrodalga firın ile saç kurutma makinesi bir grupta buzdolabı ile vantilatör başka bir grupta toplanmaktadır. Ancak 2. senaryoda mikrodalga firın ile tost makinesine ek olarak dizüstü bilgisayar ile monitör, 3. Senaryoda ise ek olarak bilgisayar kasası ile vantilatörün aynı grupta toplandığı görülmektedir. Buzdolabı ve vantilatörün 5. ve 7. harmonik bileşenlerinde, dizüstü bilgisayar ile monitörün 9., 11. Ve 13. harmonik bileşenlerinde, bilgisayar kasası ile vantilatörün ise 2., 3. ve 5 . harmonik bileşenlerinde net farklar ölçülmüștür.

Tablo 4. Kümeleme sonucunda aynı kümede toplanan evsel cihazlar.

\begin{tabular}{|c|c|c|c|}
\hline & \multicolumn{2}{|r|}{ Grup Sayısı } \\
\hline & & 16 & 15 \\
\hline \multirow{5}{*}{ 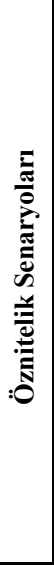 } & $1(\mathrm{P}, \mathrm{Q}, \mathrm{S})$ & $\begin{array}{c}\text { Mikrodalga firnn } \\
\text { saç kurutma makinesi }\end{array}$ & $\begin{array}{c}\text { Mikrodalga firın / saç kurutma makinesi } \\
+ \\
\text { Buzdolabı / Vantilatör }\end{array}$ \\
\hline & $2(\mathrm{P}, \mathrm{Q}, \mathrm{PF})$ & \multirow{3}{*}{$\begin{array}{l}\text { Mikrodalga firın } \\
\text { Tost makinesi }\end{array}$} & $\begin{array}{c}\text { Mikrodalga firın / Tost makinesi } \\
+ \\
\text { Dizüstü bilgisayar / Monitör }\end{array}$ \\
\hline & $3\left(\mathrm{P}, \mathrm{Q}, \mathrm{PF}, \mathrm{THD}_{\mathrm{i}}\right)$ & & $\begin{array}{c}\text { Mikrodalga firın / Tost makinesi } \\
+ \\
\text { Bilgisayar kasası / Vantilatör }\end{array}$ \\
\hline & $\begin{array}{l}4\left(\mathrm{P}, \mathrm{Q}, \mathrm{PF}, \mathrm{THD}_{\mathrm{i}}, \mathrm{H} 2, \mathrm{H} 3\right) \\
5\left(\mathrm{P}, \mathrm{Q}, \mathrm{S}, \mathrm{PF}, \mathrm{THD}_{\mathrm{i}}, \mathrm{H}(2,3,5,7)\right) \\
6\left(\mathrm{P}, \mathrm{Q}, \mathrm{S}, \mathrm{PF}, \mathrm{THD}_{\mathrm{i}}, \mathrm{H}(2,3,5,7,9,11)\right) \\
7\left(\mathrm{P}, \mathrm{Q}, \mathrm{S}, \mathrm{PF}, \mathrm{THD}_{\mathrm{i}}, \mathrm{H}(2,3,5,7, \ldots, 15)\right) \\
8\left(\mathrm{P}, \mathrm{Q}, \mathrm{S}, \mathrm{PF}, \mathrm{THD}_{\mathrm{i}}, \mathrm{H}(2,3,5,7, \ldots, 21)\right)\end{array}$ & & $\begin{array}{c}\text { Mikrodalga firın / Tost makinesi } \\
+ \\
\text { Buzdolabi / Vantilatör }\end{array}$ \\
\hline & $9\left(\mathrm{P}, \mathrm{Q}, \mathrm{S}, \mathrm{PF}, \mathrm{cosphi}, \mathrm{THD}_{\mathrm{i}}, \mathrm{H}(2,3,5,7, \ldots, 21)\right)$ & $\begin{array}{c}\text { Mikrodalga firın } \\
\text { saç kurutma makinesi }\end{array}$ & $\begin{array}{c}\text { Mikrodalga firın / Saç kurutma makinesi } \\
+ \\
\text { Buzdolabı / Vantilatör }\end{array}$ \\
\hline
\end{tabular}

Kümeleme sonuçları göstermektedir ki, 17 cihazın enerji tüketimlerinin genel olarak belirgin faklara sahip olmasından dolayı tek olarak alt gruplara dağıldı ̆̆ını, aynı alt gruplarda toplanan cihazların ise harmonik bileşenlerinde belirgin farklar görülmektedir. Bu durum, yeterli sayıda ve hassas öznitelik seçimi cihazların enerji tüketim karakterlerini ayrıştırmak için kritik öneme sahiptir göstermektedir. 


\section{Sonuç ve Öneriler}

Elektrik enerjisinin evsel kullanımının hızla artması ve yeni teknolojilerin eklenmesi, bu yükleri izleme ve denetleme ihtiyacını da beraberinde getirmektedir. Hem ekonomik hem de etkin bir şekilde bu problemi çözmek için makine öğrenmesi algoritmaları öne çıkmaktadır. Ancak bu algoritmaları uygulamak için ilk olarak cihazların özniteliklerini belirlemek gerekmektedir.

17 adet evsel cihazın temel elektriksel güç parametreleri $(\mathrm{S}, \mathrm{P}, \mathrm{Q}, \ldots)$ ve harmonik bileşenleri, Akıllı Ev laboratuvarında gerçek ölçümler yapılarak belirlenmiştir. Bu ölçümler, öznitelik olarak K-Means algoritmasında kullanılarak kümeleme analizi yapılmıştır. Analiz sonucunda farklı kümelemeler için SSE değerleri incelenmiş ve yeterli sayıda öznitelik dikkate alındığında her bir cihazın farklı örüntüye sahip olduğu gözlemlenmiştir. Bu sonuç, merkezi bir noktadan ayrıntılı ölçümler neticesinde her bir evsel cihazın toplam yük içerisinden bulunabileceğini göstermektedir.

Makine öğrenmesi algoritmalarının evsel yük izleme sistemlerine dahil edilmesi sayesinde, yüklerin izlenmesi ve denetlenmesi daha az maliyetli ve daha kolay olacaktır. Bu da, gerçek zamanlı tarifelendirme ve yük kaydırma gibi talep cevabı uygulamalarına geçişi hızlandıracaktır.

\section{Kaynaklar}

[1] Kekezoğlu B, Bozkurt A, Arıkan O, Kocatepe C, Yumurtacı R, Baysal M. Assessment of Power Quality Terms on Energy Distribution Systems: A Case Study of Istanbul. Prz. Elektrotechniczny 2012; 88(11): 157-160.

[2] Utley JI, Shorrock LD. Domestic energy fact file 2008. United Kingdom: Department of Energy and Climate Change 2008.

[3] Ehrhardt-Martinez K, Donnelly KA. Advanced Metering Initiatives and Residential Feedback Programs: A Meta-Review for Household Electricity-Saving Opportunities. USA: American Council for an Energy-Efficient Economy 2010.

[4] Hart GW. Nonintrusive Appliance Load Monitoring. Proceedindg of the IEEE 1992; 80(12): 1870-1891.

[5] Zoha A, Gluhak M, Imran MA, Rajasegarar S. Non-intrusive Load Monitoring approaches for disaggregated energy sensing: A survey. Sensors 2012; 12(12): 16838-16866.

[6] Selvam MM,Gnanadass R, Padhy NP. Fuzzy based clustering of smart meter data using real power and THD patterns. Energy Procedia 2017; 117: 401-408.

[7] Huang SJ, Hsieh CT, Kuo LC, Lin CW, Chang CW, Fang SA. Classification of home appliance electricity consumption using power signature and harmonic features. IEEE PEDS 2011; 5-8 December 2011; Singapore. pp. 596-599.

[8] Yang J, Yang Y, Chen J, Fu L, He Z. Determining the harmonic contributions of multiple harmonic sources using data clustering analysis. 2015 International Symposium on Smart Electric Distribution Systems and Technologies (EDST); 811 September 2015; Vienna, Austria. pp. 405-411.

[9] Kelly J, Knottenbelt W. Neural NILM: Deep neural networks applied to energy disaggregation. Neural and Evolutionary Computing; 4-5 November 2015; Seoul, South Korea. pp. 55-64.

[10] Altrabalsi H, Stankovic L, Liao J, Stankovic V. A low-complexity energy disaggregation method: Performance and robustness. 2014 IEEE Symposium on Computational Intelligence Applications in Smart Grid (CIASG); 9-12 December 2014; Orlando, FL, USA. pp. 1-8.

[11] Wang Y, Chen Q, Zhang M, Wang k Zhao Y. Load profiling and its application to demand response: A review. Tsinghua Science and Technology 2015; 20(2): 117-129.

[12] Egarter D, Bhuvana VP, Elmenreich W. PALDi: Online load disaggregation via particle filtering. IEEE Transactions on Instrumentation and Measurement 2015; 64(2): 467-477.

[13] Machlev R, Levron Y, Beck Y. Modified Cross-Entropy Method for Classification of Events in NILM Systems. IEEE Transactions on Smart Grid 2019; 10(5): 4962-4973.

[14] Çakmak Z, Uzgören N, Keçek G. Kümeleme Analizi Teknikleri ile İllerin Kültürel Yapılarına Göre Sınıflandırılması ve Değişimlerin İncelenmesï 2005; 2005(12).

[15] Loohach R, Garg K. Effect of Distance Functions on Simple K-means Clustering Algorithm. International Journal of Computer Applications 2012; 49(6): 7-9.

[16] Omran MGH, Engelbrecht AP, Salman A. An overview of clustering methods. Intelligent Data Analysis 2007; 11(6): 583 605.

[17] Arillaga J, Watson NR. Power System Harmonics. 2nd ed. New York, NY, USA: Wiley, 2003.

[18] Çayır A, Yenidoğan I, Dağ H. Konutların günlük elektrik güç tüketimi tahmini için uygun model seçimi. Fırat Üniversitesi Mühendislik Bilimleri Dergisi 2018; 30(3): 15-21.

[19] Sun M, Nakoty FM, Liu Q, Liu X, Yang Y, Shen T. Non-Intrusive load monitoring system framework and load disaggregation algorithms: A survey. 2019 International Conference on Advanced Mechatronic Systems (ICAMechS); 26-28 August 2019; Kusatsu, Shiga, Japan. pp. 284-288

[20] Rashid H, Singh P, Stankovic V, Stankovic L. Can non-intrusive load monitoring be used for identifying an appliance's anomalous behaviour. Applied Energy 2019; 238, 796-805. 